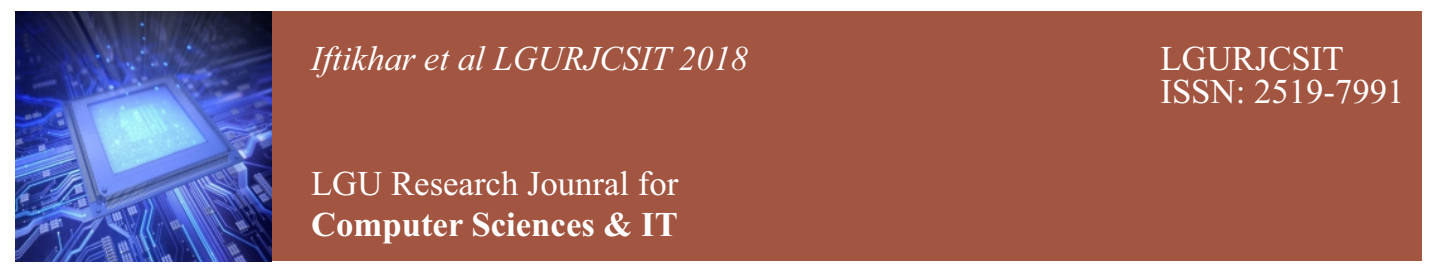

Vol. 2 Issue 4, October - December 2018

\title{
Dengue Fever: How Aware Are We? \\ A Qualitative Study of the Knowledge and Preventive Measures Against Dengue in Lahore \\ Aqsa Iftikhar
}

Kinnaird College for Women University, Jail Road, Lahore, Pakistan aqsachaudhary1@hotmail.com

\section{Abstract}

Dengue fever is an emerging contagious disease which has proved to be potentially lifethreatening. It is significant to uphold good personal and environmental hygiene in order to inhibit the outbreak of such a disease. Dengue fever (DF) is a severe febrile disease which is caused by dengue virus transferred by the female Aedes mosquito. This is one of the leading causes of death in Asian countries. The natural science of dengue infections is sturdily related with human activities and habits. The paper is designed across a study which was intended to evaluate the knowledge, attitude, and practice of people regarding dengue disease in Lahore, including the urban and sub-urban regions. A suitable sample of 200 residents (of Lahore city) is considered as contributors in study. Most of the respondents had good acquaintance with the causes, indications, mode of transmission of the virus as well as precautionary measures about dengue fever. Most prevalent precautionary method was the use of coils, liquid vaporizers. Health professional and television/radio proved to be the significant sources of information for the disease. Outcomes proposed that better awareness does not essentially lead to improved practice of dengue measures. Government educational campaigns should give more importance in providing variety of information sources, skills and support to improve dengue awareness among residents.

\section{Keywords}

Dengue, preventive measures, practices, awareness, health care.

\section{INTRODUCTION}

In recent years Dengue Fever has become a prevalent global health concern that has increased tremendously in tropical and subtropical regions of the world. Whether in urban or semi-urban areas, incidence of Dengue fever is attributed to pre-urbanization, crowded areas and intensified mosquito population due to the lack of proper waste management and changing climatic conditions. Other factors that contribute to spreading this disease include rapid growth of human population, absence of awareness among people, environmental and social changes. Water storage drums, flower vases, cement tanks; whether plastic or metal, tires, bottles, tin cans and other such rejected vessels which can hold rainwater are the source for the breeding of Aedes mosquitoes.[1]

Dengue Fever has become prevalent in most parts of the Asian subcontinent. In Pakistan,

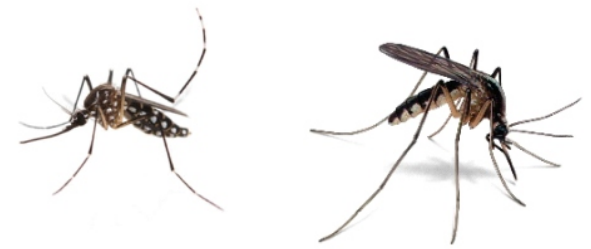

Figure 1: Dengue Mosquito (L) vs Ordinary mosquito (R)@Amazon-Images

Dengue Fever has been around for almost 20 years. The first major epidemic took place in 2011. The province of Punjab was greatly affected by it, as more than 30,000 people were diagnosed with Dengue Fever. According to the health department of Pakistan, 1816 cases were from Punjab, among which Lahore alone had 1600 cases. [2]

Dengue Fever caused by Aedes mosquito 
has become a very common epidemic in our country. The fever cannot be spread from person to person directly but is transmitted to humans as a result of the bite of an infested Aedes mosquito. Indications of infection are characterized by an unexpected beginning of high fever $\left(103-106^{\circ} \mathrm{F}\right)$, severe headache, extreme pain in joints and muscles, patient feeling nausea and occasional vomiting and a general rash that usually begin 4 to 7 days after the mosquito bite and typically lasts till 3 to 10 days. It has appeared as a notable public health concern in recent years. Minor bleeding complications can also follow.[3]

The indications usually go away totally within 1 to 2 weeks of the bite. Dengue infection without clear indications tends to happen commonly among children while in adults it is likely to be symptomatic.

In the absence of a proper treatment or vaccine to treat Dengue Fever, the only prevent reduce this disease is vector control. Vector control approaches can be effective, only if there is community involvement, and for the success of such programs that involve community members, it is imperative to measure the community's discernment concerning the disease, its mode of transmission and most importantly the common breeding sites.

\section{MATERIALS AND METHODS}

\section{A. Description of Sample}

The study was conducted among the inhabitants of Lahore; belonging to urban and semi-urban areas mostly. Age group was carefully chosen to be 25 years and above. Google Docs was used for the data assemblage. Online questionnaire was circulated through social networks, through email, through universities portals and through different mediums. Analysis was performed by applying statistical hypothesis and presented with the help of PYTHON 3 grounded on the survey data.

The questionnaire was divided into four sections which included:

i. Demographics details of the respondents namely age group, marital status and Profession the respondent is working in and monthly income.

ii. Experience with dengue Knowledge and attitudes about the disease.

iii. Knowledge and attitudes about the disease iv. Practices related to prevention against dengue.

\section{B. Data Collection}

The questionnaire was distributed to the inhabitants belonging to various parts of Lahore. A total of 50 were distributed by hand and 150 were filled online. 200 filled questionnaires were collected at the end.

\section{C.Scope}

The scope of our study was limited to the inhabitants of Lahore. People belonged to various areas of Lahore filled the questionnaire online and face-to-face.

\section{RESULTS AND DISCUSSION}

\section{A. Basic demographic features}

Among the 200 respondents most of them were male $(55.4 \%)$ while female only constituted $(44.6 \%)$ of the total. Maximum number of respondents belonged to the age group of 26 to $35(49.7 \%)$. Considerable majority of respondents were graduates $(82 \%)$. Out of the total participants $47.9 \%$ participants had a full time job. Monthly household income of the majority of people was above Rs. 35,000. Most of the respondents lived in the urban area $(69.0 \%)$ of the city and mainly had individual houses $(55.5 \%)$. Table 1 describes the demographics of the study population. The tables give the detailed information regarding the features mentioned above. 
Table 1: Demographic Features

\begin{tabular}{|c|c|c|}
\hline Statement & Frequency & Percentage $\%$ \\
\hline \multicolumn{3}{|l|}{ Gender: } \\
\hline$\overline{\text { Male }}$ & 108 & 55.4 \\
\hline Female & 87 & 44.6 \\
\hline Total & 195 & 100.0 \\
\hline \multicolumn{3}{|l|}{ Age: } \\
\hline$\overline{\text { Below } 25}$ & 68 & 34.9 \\
\hline 26 to 35 & 97 & 49.7 \\
\hline 36 to 45 & 13 & 6.7 \\
\hline 46 to 55 & 10 & 5.1 \\
\hline Above 56 & 7 & 3.6 \\
\hline Total & 195 & 100.0 \\
\hline \multicolumn{3}{|l|}{ Marital Status: } \\
\hline$\overline{\text { Single }}$ & 96 & 49.5 \\
\hline Married & 98 & 50.5 \\
\hline Total & 194 & 100.0 \\
\hline \multicolumn{3}{|l|}{ Level of Education: } \\
\hline$\overline{\text { Graduate (University level) }}$ & 159 & 82 \\
\hline Secondary education & 23 & 11.9 \\
\hline Primary education & 7 & 3.6 \\
\hline No formal education & 5 & 2.5 \\
\hline Total & 194 & 100.0 \\
\hline \multicolumn{3}{|l|}{ Occupation: } \\
\hline$\overline{\text { Full time }}$ & 93 & 47.9 \\
\hline Part time & 17 & 8.8 \\
\hline Student & 49 & 25.3 \\
\hline House wife & 20 & 10.3 \\
\hline Unemployed & 15 & 7.7 \\
\hline Total & 194 & 100.0 \\
\hline \multicolumn{3}{|l|}{ House hold income: } \\
\hline$\overline{\text { Below } 15000}$ & 22 & 11.6 \\
\hline Between 15000 to 25000 & 31 & 16.4 \\
\hline Between 25000 to 35000 & 30 & 15.9 \\
\hline Above 35000 & 106 & 56.1 \\
\hline Total & 189 & 100.0 \\
\hline \multicolumn{3}{|l|}{ Which of the following best } \\
\hline \multicolumn{3}{|l|}{ describes the area you live in? } \\
\hline$\overline{\text { Urban (city or town) }}$ & 138 & 69.0 \\
\hline $\begin{array}{l}\text { Suburban (situated on the } \\
\text { outer parts of a city) }\end{array}$ & 37 & 18.5 \\
\hline Rural (countryside) & 25 & 12.5 \\
\hline Total & 200 & 100.0 \\
\hline \multicolumn{3}{|l|}{ What type of house you live in? } \\
\hline$\overline{\text { Housing Authorities (Colonies) }}$ & 47 & 23.5 \\
\hline Flats/ Apartments & 18 & 9.0 \\
\hline $\begin{array}{l}\text { Individual House (single } \\
\text { homes) }\end{array}$ & 111 & 55.5 \\
\hline Private quarters & 4 & 2.0 \\
\hline None of the above & 20 & 10.0 \\
\hline Total & 200 & 100.0 \\
\hline
\end{tabular}




\section{B. Awareness on Dengue Spread, Symptom and Treatment}

Data enlightening the responsiveness towards dengue transmission, its symptoms and treatment are clearly stated in Table 2 . Majority $(81.5 \%)$ of the respondents had been diagnosed with the symptoms of dengue. About $36 \%$ answered that it took less than 5 days to recover and $41 \%$ were aware that it is caused by Aedes mosquito. When asked about the common symptoms, fever was the most consistent response (65\%).

Table 2: Awareness on Dengue Spread, Symptom and Treatment

\begin{tabular}{|c|c|c|}
\hline Statement & Frequency & Percentage $\%$ \\
\hline \multicolumn{3}{|c|}{ Have you ever been diagnosed with dengue fever? } \\
\hline Yes & 163 & 81.5 \\
\hline No & 37 & 18.5 \\
\hline Total & 200 & 100.0 \\
\hline \multicolumn{3}{|c|}{ How many days did it take to recover from the fever? } \\
\hline Less than 5 days & 72 & 36.0 \\
\hline 5 to 10 days & 47 & 23.5 \\
\hline 11 to 15 days & 46 & 23.0 \\
\hline More than 15 days & 35 & 17.5 \\
\hline Total & 200 & 100.0 \\
\hline \multicolumn{3}{|c|}{ What type of mosquito causes dengue fever? } \\
\hline Aedes & 82 & 41.0 \\
\hline Anopheles & 14 & 7.0 \\
\hline Culex & 7 & 3.5 \\
\hline Culiseta & 8 & 4.0 \\
\hline - & 89 & 44.5 \\
\hline Total & 200 & 100.0 \\
\hline \multicolumn{3}{|c|}{ How is dengue fever transmitted to the individuals? } \\
\hline Mosquito bite & 151 & 75.5 \\
\hline Air borne (Person to person) & 5 & 2.5 \\
\hline Water borne & 11 & 5.5 \\
\hline Blood transfusion & 17 & 8.5 \\
\hline Don't know & 16 & 8.0 \\
\hline Total & 200 & 100.0 \\
\hline \multicolumn{3}{|c|}{ What are the signs and symptoms of dengue fever? } \\
\hline High fever & 130 & 65.0 \\
\hline Nausea and vomiting & 21 & 10.5 \\
\hline Fatigue (tiredness) & 14 & 7.0 \\
\hline Diarrhea & 10 & 5.0 \\
\hline Other & 25 & 12.5 \\
\hline Total & 200 & 100.0 \\
\hline \multicolumn{3}{|c|}{$\begin{array}{l}\text { What are the common problems faced by the patients } \\
\text { with dengue fever? }\end{array}$} \\
\hline Dengue hemorrhagic fever & 39 & 20.0 \\
\hline Dehydration & 6 & 3.1 \\
\hline Low platelets count & 118 & 60.5 \\
\hline Shock /Death & 7 & 3.6 \\
\hline Don't know & 25 & 12.8 \\
\hline Total & 195 & 100.0 \\
\hline
\end{tabular}

\section{Knowledge of Vector Characteristics and Preventive Measures}

About (32\%) of those interviewed were familiar of the fact that the dengue mosquito breeds in clean s water in the open water tanks. Most of the people believed that the mosquito typically bites at sunset/dusk (43\%).

Most participants considered wearing long sleeved clothing (45.5\%) and mosquito sprays and ointments $(34.4 \%)$ as the most common choices for prevention.Data showing the magnitude of knowledge concerning vector breeding sites, mosquito bite time and preventive practices all are presented in Table 3. 
Table 3: Knowledge of Vector Characteristics and Preventive

Statement

Frequency

Percentage\%

\begin{tabular}{lccc}
\hline At what time of day & the dengue mosquito most active to & & 15.5 \\
\hline bite? & & 31 & 43.0 \\
Day time & & 86 & 17.5 \\
Evening time & 35 & 14.0 \\
Night time & Total & 28 & 10.0 \\
Anytime of day & & 20 & 100.0 \\
Don't know & & 200 & 100
\end{tabular}

Where do you think the mosquito is most likely to breed

in your house?

\begin{tabular}{lll}
\hline In the tray under the refrigerator & 41 & 20.5
\end{tabular}

In the plant pots $\quad 37 \quad 18.5$

$\begin{array}{lll}\text { In the water containers } & 40 & 20.0\end{array}$

In the open water tanks $\quad 34.0$

Other

Total

200

What are the most common breeding sites for the dengue

carrier mosquito in the open?

Stagnant water (in tires etc)

Garbage piles

Uncovered manholes

Uncovered water reservoirs

Other

$$
\text { Total }
$$

$\begin{array}{cc}86 & 43.0 \\ 12 & 6.0 \\ 16 & 8.0 \\ 59 & 29.5 \\ 27 & 13.5 \\ 200 & 100.0\end{array}$

In which of the following areas are you most likely to catch dengue fever when travelling?

Desert areas

$7 \quad 3.6$

Mountainous areas (lots of trees)

Areas with heavy rainfall

Other areas

$97 \quad 49.5$

Don't know

$29 \quad 14.8$

$45 \quad 22.9$

\section{Total}

196

22.9

How would you prevent yourself from mosquito bites?

Wearing long sleeved clothing

Mosquito repellent ointments and sprays

$79 \quad 40.5$

Mosquito nets

$67 \quad 34.4$

Mosquito coils/mats

$23-11.8$

$26 \quad 13.3$

\section{Total}

195

100.0

How would you prevent mosquito breeding in your home and garden?

Use of smoke to drive away mosquitoes

Cover water containers tightly

Changing water from plant pots at least once a week

Keep garbage in closed bins

\section{Total}

$\begin{array}{cc}42 & 21.2 \\ 99 & 50.0 \\ 41 & 20.7 \\ 16 & 8.1 \\ 198 & 100.0\end{array}$

What measures would you take to prevent dengue outbreak in your neighborhood?

$\begin{array}{lll}\text { Leveling ground surfaces to avoid the accumulation of } & 72 & 37.1\end{array}$ water.

Insecticide sprays reduce mosquitoes.

$90 \quad 46.4$

Cutting down bushes (long grass)

17

15

8.8

Burning garbage

$$
\text { Total }
$$

194

100.0




\section{Information Regarding Dengue Fever}

About $37.5 \%$ said that they got aware of the disease through television and radio while $35 \%$ stated that they got the related information through health professionals. While Google topped the list of most searched places by the respondents to look for information regarding the disease (38.6\%). Most of the people were satisfied by the amount of informationprovided by the Government (69.9\%) through media and campaigns against dengue.

\section{E. Hypothesis Development and Analysis}

Some hypothesis were applied to a few questions from our survey and verified by estimation techniques in statistics. A common interval for? that is $95 \%$ was used. Here is the list of hypotheses:

Table 4: Hypothesis development of Respondents

Hypothesis Development
H0A: About half of the population is diagnosed with dengue fever.
H1A: Greater than half of the population has been diagnosed with dengue fever.
H0B: Dengue mosquito is most active at day time.
H1B: Dengue mosquito is not active at day time.
H0C: The majority of population ( $50 \%$ ) believes it takes less than 5 days to recover from the
fever.
H1C: Less than $50 \%$ believes it takes less than 5 days to recover from the fever.
H0D: Majority $(50 \%)$ of the population does not know that dengue is caused by Aedes mosquito.
H1D: Less than $50 \%$ of the population does not know that dengue is caused by Aedes mosquito.

H0E: Monsoon is most likely th e season in which dengue spreads the most as compared to summer.

H1E: Dengue is more widely spread in summer.

H0F: Half of the population is of the view that dengue is transferred through mosquito bite.

H1F: More than half of the population is of the view that dengue is transferred through mosquito bite.

H0G: High fever appears to be a major symptom of dengue fever (about 70\%)

H1G: less than $70 \%$ believed that high fever is a symptom of dengue fever.

HOH: Common problem faced by the patients with dengue fever is low platelets count $(\mathrm{p}=0.50)$

H1H: More than $50 \%$ is of the view that common problem faced by the patients with dengue fever is low platelets count.

H0I: Equal to $40 \%$ of the population thinks that the medicine advised during dengue fever is Paracetamol.

H1I: Not equal to $40 \%$ of the population thinks that the medicine advised during dengue fever is Paracetamol.

H0J: Half of the population thinks that wearing long sleeved clothing saves you from mosquito bite.

H1J: Less than half of the population $t$ hinks that wearing long sleeved clothing saves you from mosquito bite.

H0K: About $40 \%$ of the population thinks that using Insecticide sprays reduce mosquitoes.

H1K: Greater than $40 \%$ of the population thinks that using Insecticide sprays reduce mosquitoes.

HOL: Equal to $70 \%$ of the population of dengue patient in the survey satisfied with the level of information provided by the government regarding the prevention of dengue fever.

H1L: Equal to $70 \%$ of the population of dengue patient in the survey not sati sfied with the level of information provided by the government regarding the prevention of dengue fever. 
Table 5: Hypothesis Analysis of Respondents

\begin{tabular}{|c|c|c|c|c|}
\hline Hypothesis & p-interval & z-cal & $z-$ tab & Result \\
\hline $\begin{array}{l}\text { H0A: About half of the } \\
\text { population is diagnosed with } \\
\text { dengue fever. } \\
\text { H1A: Greater than half of the } \\
\text { population has been diagnosed } \\
\text { with dengue fever. }\end{array}$ & $0.762-0.869$ & 9 & $\begin{array}{c}1.645 \\
\text { One-tail test }\end{array}$ & $\begin{array}{c}\text { H1A } \\
\text { Accepted }\end{array}$ \\
\hline $\begin{array}{l}\text { H0B: Dengue mosquito is most } \\
\text { active at day time. } \\
\text { H1B: Dengue mosquito is not } \\
\text { active at day time. }\end{array}$ & $0.104-0.206$ & $|-9.9|=9.9$ & $\begin{array}{c}1.96 \\
\text { Two-tail test }\end{array}$ & $\begin{array}{c}\text { H1B } \\
\text { Accepted }\end{array}$ \\
\hline $\begin{array}{l}\text { H0C: The majority of population } \\
(50 \%) \text { believes it takes less than } \\
5 \text { days to recover from the fever. } \\
\text { H1C: Less than } 50 \% \text { believes it } \\
\text { takes less than } 5 \text { days to recover } \\
\text { from the fever. }\end{array}$ & $0.293-0.427$ & -4 & $\begin{array}{c}-1.645 \\
\text { One-tail test }\end{array}$ & $\begin{array}{c}\text { H1C } \\
\text { Accepted }\end{array}$ \\
\hline $\begin{array}{l}\text { H0D: Greater than and equal to } \\
(40 \%) \text { of the population does not } \\
\text { know that dengue is caused by } \\
\text { Aedes mosquito. } \\
\text { H1D: Less than } 40 \% \text { of the } \\
\text { population does not know that } \\
\text { dengue is caused by Aedes } \\
\text { mosquito. }\end{array}$ & $0.341-0.479$ & 0.29 & $\begin{array}{c}-1.645 \\
\text { One-tail test }\end{array}$ & $\begin{array}{c}\text { HOD } \\
\text { Accepted }\end{array}$ \\
\hline $\begin{array}{l}\text { H0E: Monsoon is most likely the } \\
\text { season in which dengue spreads } \\
\text { the most (less than and equal to } \\
50 \% \text { ). } \\
\text { H1E: There is a greater than } 50 \% \\
\text { chance that dengue is more } \\
\text { widely spread in Monsoon. }\end{array}$ & $0.386-0.524$ & -1.29 & $\begin{array}{c}1.645 \\
\text { One-tail test }\end{array}$ & $\begin{array}{c}\text { HOE } \\
\text { Accepted }\end{array}$ \\
\hline
\end{tabular}

HOF: Half of the population is of the view that dengue is transferred through mosquito bite.

H1F: More than half of the population is of the view that

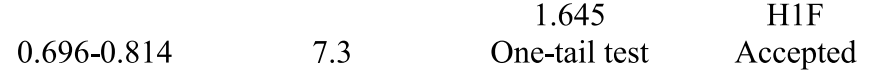
dengue is transferred through mosquito bite.

H0G: High fever appears to be a major symptom of dengue fever

(about 70\%)

H1G: less than $70 \%$ believed that high fever is a symptom of 
H0H: Common problem faced by the patients with dengue fever is low platelets count $(\mathrm{p}=0.50)$

H1H: More than $50 \%$ is of the

view that common problem faced by the patients with dengue fever is low platelets count.

H0I: Equal to $30 \%$ of the population thinks that the medicine advised during dengue fever is Paracetamol.

H1I: Not equal to $30 \%$ of the population thinks that the medicine advised during dengue fever is Paracetamol.

H0J: Half of the population thinks that wearing long sleeved clothing saves you from mosquito bite.

H1J: Less than half of the population thinks that wearing long sleeved clothing saves you from mosquito bite.

H0K: Greater than and equal to $40 \%$ of the population thinks that using insecticide sprays reduce mosquitoes.

H1K: Less than $40 \%$ of the population thinks that using Insecticide sprays reduce mosquitoes.

HOL: Half of the population of dengue patient in the survey satisfied with the level of information provided by the government regarding the prevention of dengue fever. H1L: More than half of the population of dengue patient in

HOL: Half of the population of dengue patient in the survey satisfied with the level of information provided by the government regarding the prevention of dengue fever. H1L: More than half of the population of dengue patient in

H1L the survey not satisfied with the level of information provided by the government regarding the prevention of dengue fever. 


\section{CONCLUSION}

KAP survey [2] inspired me to conduct this study for the inhabitants of Lahore. In contrast to KAP, my survey is performed with a more detailed questionnaire and the responses are evaluated not only on p-value but a detailed post-survey statistical analysis is also presented in this paper. However it supports the weak association between dengue knowledge and the preventive measures adopted by the community as indicated by KAP survey.

It could be inferred from this research that the level of awareness among the participants about dengue fever and its precautionary practices is rather satisfactory. It is promising to learn from our study that most of the inhabitants of Lahore had the knowledge that Dengue Fever can be treated by several means and people have affirmative attitude towards the treatment. Almost all thought that they should visit a doctor when they comprehended they were suffering from Dengue Fever given the characteristic symptoms.

However, people don't tend to put this knowledge into practice. Better knowledge does not essentially leads to better practice, apparently because it is hard to change a person's conduct due to several social and cultural issues like water storing practices, sleeping outdoor due to load shedding, absence of resources to adopt cautionary measures like covering windows with nets, large container with lids.

Making health information easier to comprehend can help increase the knowledge and awareness of the public. Organizing more public cleaning activities can also increase people's awareness that keeping clean and healthy surroundings involves teamwork from each person. [4]

Retaining a hygienic environment is not entirely the Government's responsibility. Effective disease control and prevention cannot be attained without the support of the community.

Information, education and communication resources maybe provided in schools and health centers making it more available for the inhabitants to acquire. Familiarity with dengue fever, its vectors and transmission of infection may be incorporated into the school syllabus especially in areas where dengue is extremely dominant. Health professionals should be qualified to give more suitable counseling in a struggle to change certain deep-rooted habits. Radio and television must also showcase a significant role in carrying health information to the community, and regular visits of health personnel to schools and colleges are necessary as well. Thus, understanding people views and practices could help in recognizing the target areas to control dengue outbreaks. [5]

\section{References}

[1] Geetu Malhotra, Aman Yadav, Puja Dudeja, "Knowledge, Awareness and Practices Regarding Dengue Fever among Rural and Slum Communities in North Indian City, India”, 2014.

[2] Farah Rashid Siddiqui, Abdul Qadir Usmani, Iffat Atif, S. Hassan Bin Usman, Syed Hammad Haider, "Are We Aware of Dengue Fever? A Community Based KAP Survey on Dengue Fever in Rawalpindi”, 2008.

[3] Gunasekara TDCP, Velathanthiri VGNS, Weerasekara MM, Fernando SSN, Peelawattage M, GurugeD, Fernando S, "Knowledge, attitudes and practices regarding dengue fever in a suburban community in Sri Lanka", 2015.

[4] Dr. Bushra Yasmeen, Dr. Nermeen Jamshaid, Dr. Muhammad Zohaib Khan, Dr. Munnaza Salman, Dr. Raza Ullah, "Effectiveness of Dengue Fever Prevention Campaigns: A study of knowledge and practices in Urban/Semi-Urban Communities of Lahore", 2015.

[5] Ahmed Itrat, Abdullah Khan, Sunniya Javaid, Mahwash Kamal, Hassan Khan, Sannia Javed, Saira Kalia, Adil Haleem Khan, Muhammad Imran Sethi, and Imtiaz Jehan, "Knowledge, Awareness and Practices Regarding Dengue Fever among the Adult Population of Dengue Hit Cosmopolitan”, 2008. 